\title{
A decisive decade
}

\author{
The climate and biodiversity crises are two sides of the same coin demanding urgent, ambitious action. Countries \\ must commit to halve their carbon emissions and effectively protect 30\% of land and oceans by 2030 .
}

T

he much-anticipated twenty-sixth United Nations Climate Change Conference of the Parties (COP26) takes place this month in Glasgow, UK. This is the most important climate summit since the 2015 Paris Agreement on climate change, where all 196 parties committed to regularly discussing ambitious plans to reduce carbon emissions and restrain global temperature increases within $1.5-2{ }^{\circ} \mathrm{C}$ of pre-industrial levels. It has since become clear that achieving the $1.5^{\circ} \mathrm{C}$ temperature cap is essential if we are to live in a functional, healthy planet. To meet this goal, we must reach net zero carbon emissions by 2050 , which is only possible if countries halve their carbon emissions by 2030 . The ambition and urgency needed to avert the climate crisis cannot be overstated - we must change a trajectory from still-rising to halved emissions in just eight years.

COP26 is structured around four goals: mitigation, adaptation, finance and collaboration. Mitigation encapsulates the emission reductions needed to achieve global net zero by mid-century. Adaptation represents plans to protect and restore ecosystems while making natural systems and human infrastructure resilient to climate change. The last two goals, finance and collaboration, speak to the need to commit financial resources and mobilize governments, businesses and civil society to tackle the climate crisis with urgency. To address these goals, we need evidence-based solutions. In anticipation of COP26, the Nature Portfolio has assembled a number of papers in a Collection that provides evidence to support decision-making related to the goals of COP26.

As stated in the mitigation goal, the transformation of the energy sector from extractive to renewable sources of energy is crucial to reduce emissions and fight the climate crisis. Equally important, and arguably less appreciated, is the key role that protecting our land and oceans plays in increasing carbon storage and avoiding greenhouse gas emissions. Indeed, nature-based solutions such as conservation, restoration and land management can provide up to one-third of the climate mitigation needed to meet the goals of the Paris Agreement ${ }^{1}$. Alongside these climate-related benefits, nature preservation will also slow the rampant pace of species extinctions which could affect a million species within decades ${ }^{2}$. Science tells us that we must protect $30 \%$ of our land and ocean by 2030 to avoid a mass extinction crisis and curb climate change. This goal, also known as $30 \times 30$, is incorporated in the draft post-2020 Global Biodiversity Framework ${ }^{3}$, which is to be finalised and adopted in April 2022 by the Convention on Biological Diversity (CBD) in Kunming, China. A piece of good news was announced in September 2021 when nine philanthropic foundations launched the 'Protecting our Planet Challenge' and pledged a record US $\$ 5$ billion towards the 30x30 campaign ${ }^{4}$.

Protecting 30\% of Earth's land and ocean is a clear goal but prioritizing the right areas to protect is not trivial; we need to pinpoint the intersection between those geographic regions that optimise biodiversity conservation and climate mitigation, while also considering human needs. In this issue, Jung et al. ${ }^{5}$ identify locations that maximize protection of terrestrial vertebrates and vascular plants as well as carbon storage and freshwater quality. The authors ranked regions according to their potential to synergistically achieve those three goals and show that protecting $30 \%$ of terrestrial land area would protect about $60 \%$ of the species considered while conserving about two-thirds of the estimated total carbon stock and clean freshwater. The authors acknowledge that their findings reflect known unevenness among countries, with many tropical countries having particularly high proportions of areas of conservation importance, and that only management actions that also adequately consider local livelihoods and knowledges are likely to be successful.

Halving carbon emissions and protecting $30 \%$ of our land and oceans in just eight years are ambitious goals, which require initial mobilization of public and private finance but the economic costs of inaction massively outweigh these necessary investments ${ }^{6}$. Finance is one of the priority concerns of COP26 and the post-2020 Global Biodiversity Framework alike. The financial system must change structurally in order to achieve net zero emissions by 2050 - it needs to stop investing in fossil fuels and allocate public and private funds to infrastructure and technology that supports a greener economy. These investments must include support for nature-based solutions, with rich countries in particular having to contribute meaningful funding to conservation and management of biodiverse areas in low- and middle-income countries. That this is a complex and perhaps distant goal is exemplified by an analysis published in this issue of the impacts on global biodiversity and Indigenous lands by financing from Chinese overseas development. Yang et al. ${ }^{7}$ found that of the 594 development projects financed by the China Development Bank and the Export-Import Bank of China in 2008 and $2009,63 \%$ are located within critical habitats, protected areas and/or Indigenous land and could impact up to $24 \%$ of the world's threatened amphibians, birds, mammals and reptiles.

This month all eyes will be on Glasgow, expecting all participating countries to up their ambition and commit to concrete plans for the rest of this decade that will make net zero by 2050 possible. Nature Ecology o Evolution remains committed to publishing papers that focus on nature-based solutions to the climate crisis.

Published online: 2 November 2021 https://doi.org/10.1038/s41559-021-01582-1

References

1. Griscom, B. W. et al. Proc. Natl Acad. Sci. USA 114, 11645-11650 (2017).

2. Global Assessment Report on Biodiversity and Ecosystem Services of the Intergovernmental Science-Policy Platform on Biodiversity and Ecosystem Services (eds Diaz, S. et al.) (IPBES Secretariat, 2019).

3. First detailed draft of the new post-2020 global biodiversity framework. CBD https://go.nature.com/3oHArXE (6 July 2021).

4. Record $\$ 5$ bn donation to protect nature could herald new green era of giving. The Guardian https://go.nature.com/3uRtd44 (29 September 2021)

5. Jung, M. et al. Nat. Ecol. Evol. https://doi.org/gmmx22 (2021).

6. The $1.5^{\circ} \mathrm{C}$ Charter. UCL https://go.nature.com/3aefXof (accessed 7 October 2021).

7. Yang, H. et al. Nat. Ecol. Evol. https://doi.org/gzmk (2021). 